\title{
Çok Kültürrlü Ortamda Çalışanların Kültürel Zekâ Düzeylerinin Duygusal Emek Gösterimlerine Etkisi
}

\author{
DOI: $10.26466 /$ opus. 584460
}

*

Deniz Devrim Tașdemir* ${ }^{*}$-Hülya Gündüz Çekmecelioğlu** - İbrahim Y1kılmaz ${ }^{* * *}$

* YL Öğr., Kocaeli Üniversitesi Sosyal Bilimler Enstitüsü,Kocaeli/Türkiye

E-Posta: dennisdevrim@hotmail.com ORCID: 0000-0001-5396-9788

** Prof.Dr., Kocaeli Üniversitesi Iktisadi ve Idari Bilimler Fakültesi,_Kocaeli/Türkiye

E-Posta: hulyacekmecelioglu@gmail.com ORCID: 0000-0002-0123-4939

*** Arş.Gör., Kocaeli Üniversitesi Iktisadi ve Idari Bilimler Fakültesi, Kocaeli/Türkiye

E-Posta: ibrahimyklmz@gmail.com

ORCID: $\underline{\text { 0000-0002-1051-0886 }}$

Öz

Çeşitli teknolojik ilerlemeler ve iş yapma şekillerindeki değişimler, çok kültürlü çalışma ortamını oluşturmuş ve bu ortamın gerektirdiği tutum ve davranışları sergileme yeteneği olarak tanımlanan kültürel zeka ve çalışan performansını belirleyen diğer önemli unsur olan duygusal emek arasında ki ilişki çok kültürlü bir örgüt yapısına sahip çalışma ortamında yer alan 101 katılımo üzerinde incelenmiştir. Sonuçlar incelendiğinde; kültürel zekânın örgüt üyelerinin duygusal emek davranışını pozitif yönde etkilediği ï üst bilişsel zeka bileşeninin duygusal emeğin yüzeysel rol yapma davranışını negatif, derin davranış ve doğal (samimi) davranış boyutunu pozitif yönde etkilediği, kültürel zekanın alt boyutlarından davranışsal kültürel zekanın, yüzeysel davranış, derin davranış ve doğal (samimi) davranışı pozitif yönde etkilediŭini göstermektedir. Araştırma sonuçları, çok kültürlü ortamda özellikle üyelerin kültürel zeka düzeyinin duygularm yönetiminde ve örgüt tarafindan istenen duygularm gösterilmesinde çok önemli bir rol oynadı̆̆ın göstermektedir. Üst düzey yöneticiler tarafindan gerek üyelerin kültürel zekâsının gerekse duygusal emek gösteriminin dikkate alınmasının stratejik insan kaynağının etkin yönetimi açısından önemli olduğu değerlendirilmektedir.

Anahtar Kelimeler: Kültürel zeka, duygusal emek, çok kültürlü çalışma ortamı 


\title{
The Effect of Cultural Intelligence Level on Emotional Labor in A Multicultural Environment
}

\begin{abstract}
Various technological advances and changes in the way of doing business have created multicultural working environments and the need for human resources being compatible with this environment. The purpose of the study is to examine the relationship between cultural intelligence and emotional labour and 101 participants working in a multicultural organization were analyzed. According to the results, $C Q$ has a positive effect on the emotional labor behavior of the members of the organization, the metacognitive CQ affects the surface acting behavior negatively and affects deep acting and genuine acting dimensions positively and behavioral CQ affects surface acting, deep acting and genuine acting positively. The results of the research show that in multicultural environment, especially the level of cultural intelligence plays a very important role in the management of emotions and the emotions desired by the organization. Taking into consideration the results obtained by decision makers is important in terms of effective management of strategic human resources.
\end{abstract}

Keywords: Cultural intelligence, Emotional labor, Multicultural environment 


\section{Giriş}

Hayatın her alanında deneyimlenen ileri teknoloji ve bunun sunduğu imkânlarla hızlı bir şekilde mekân ve şekil değiştiren sermaye, işgücü, hizmet ve fikir akışı; alışıldık çalışma ve üretme biçiminin farklılaşmasına neden olmaktadır. Bu hızlı değişim ve sınırların ötesine geçen iş yapma ve birlikte değer üretme sürecinde, sayısı her geçen gün artan çok kültürlü çalışma ortamlarını yaratmaktadır. Bu çok kültürlü çalışma ortamında, örgütlerin belirlenen amaç ve hedeflerine ulaşmasında, farklılıklardan sürdürülebilir rekabet avantajı yaratma ihtiyacı, son dönemde "kültürlerarası uyum, iş performansı, uluslararası görev süresini tamamlama, örgütsel bağhllık, kültürlerarası yeterlilik ve kültürel zekâ" gibi konuları gündeme getirmiş ve özellikle stratejik insan kaynağının etkinlik ve verimliliğinin arttırılmasına yönelik adımların belirlenmesi adına çalışmalar yoğunlaşmaya başlamıştır. Bu çalışma konularından; "bireyin yeni kültürel bağlama uyum, değerlerine ve tutumlarma uygun davranış geliştirme ve çok kültürlü ortamlarda etkili olabilme yeteneği" olarak tanımlanan zekâ kavramı, özellikle çok kültürlü ortamda örgütlerin belirledikleri amaç ve hedeflere ulaşmada kritik bir role sahip olan mevcut insan kaynağının ve örgüte katılması planlanan yeni çalışanların bu ortama uyum sağlaması, kültürel zekâlarının örgüt kültürüne uygun olup olmadığının belirlenmesi büyük önem arz etmektedir. Bireyin bu çok kültürlü ortamla kurmuş olduğu ilişkide; "duygularmı düzenlemesi, kişiler arası etkileşimde örgütün gerekli gördüğ̈̈ duyguları ifade edebilmesi, etkileşim içinde olduğu kişi ve ortamın bir parçasıymış gibi duyguların hissetme ve uygun duyguları sergileme çabası" olarak tanımlanan duygusal emek kavramı da son dönemde örgütlerin en iyi hizmeti sunma, etkinlik ve verimlilik ihtiyaçları yanında, uygun insan kaynakları stratejilerinin izlenmesi açısından da üzerinde önemle durulan bir husus haline gelmiştir.

Bu kapsamda çalışmada; kültürel zeka ve duygusal emek kavramları ve değişkenler arası ilişki literatür kısmında tartışılmış, ikinci bölümde çok kültürlü çalışma ortamına sahip uluslar arası bir kuruluş bünyesinde görev yapan katılımcıların, kültürel zeka ve duygusal emek algıları ölçülmüş, bulgular ve sonuç kısmında çalışma kapsamında incelenen örnekleme ilişkin sonuçlar paylaşılmıştır. Sonuçlar, çok kültürlü ortamlarda ki 
üyelerin kültürel zeka düzeylerinin duygusal emek davranışlarını etkilediğini göstermektedir. Bu sonuç bize bu tip ortamlarda bulunan karar alıcıların amaç ve hedeflerine ulaşmalarında, etkin kararlar alma ve sonuçlar üretmelerinde kültürel zekâ ve duygusal emeğin önemli bir rol oynadığını göstermektedir. Araştırma sonuçları, iş yaşamına pozitif katkıları olan duygusal emek davranışlarının geliştirilmesinde kültürel zekânın ayırt edici bir rol oynadığını göstermekte ve yöneticilerin dikkatini bu kavrama yöneltmektedir.

\section{Kavramsal Çerçeve}

\section{Duygusal Emek Kavramı}

Örgütsel davranış alanında fiziksel ve düşünsel emeğin yanında, duygusal emek kavramından da bahsedilmektedir. Adından ilk olarak Hochschild tarafından "The Managed Heart" kitabında bahsedilen kavram; "duyguların halka açık ortamda gözlemlenebilir yüz ve bedensel bazı davranışları sergilemek suretiyle duyguların yönetilmesi" olarak tanımlanmaktadır ( Hochschild, 1983, s.7). Sonraki süreçlerde ise, duygusal emek kavramı, farklı tanım ve boyutlandırmalarla açıklanmaya çalışılmıştır. James (1989)'e göre "duygusal emek; temel bileşeni duygularn düzenlenmesi olan ve diğerlerinin duygularıyla baş edebilme süreci içinde olma", Ashforth ve Humphrey (1993)'e göre; "uygun olan duygunun sergilenmesi", Morris ve Feldman (1996)'a göre, "Kişilerarası etkileşim sırasında örgütsel olarak gerekli duygulart ifade edebilmek için bireylerin gösterdiği çaba, yaptı̆̆ı plan ve kontrol", England ve Farkas (1996)'e göre "başkaların anlama, onların içinde bulunduğu durumlarıyla empati kurma, birinin bir parçasıymışçasına duygularımı hissetme çabası", Kruml ve Geddes (2000)'a göre "çalışanların işe entegre olma süreçlerinde hissetmek zorunda oldukları birtakım çaba", Eroğlu (2010)'na göre ise, " çalışanın, çalıştığı örgüt tarafindan belirlenen kuralları uygularken, paydaşına en iyi şekilde hizmet verebilmek maksadıyla uygun duygunun hissedilmesi ve aktarılması çabası" süreci olarak tanımlanmaktadır. Duygusal emek kavramına ilişkin farklı tanımlar ve çalışmalar mevcut olup, bu kavramın boyut ve modellerine ilişkin özet, Tablo 1'de sunulmuştur. 
Tablo 1: Duygusal emek kavramına ilişkin farklı tanımlar ve çalışmalara ilişkin özet( Savaş, 2012)

\begin{tabular}{|c|c|c|c|}
\hline $\begin{array}{l}\text { Hochschild } \\
\text { (1983) }\end{array}$ & $\begin{array}{l}\text { Ashforth ve Humphrey } \\
\text { (1993) }\end{array}$ & $\begin{array}{l}\text { Morris ve Feldman } \\
\text { (1996) }\end{array}$ & Grandey (2000) \\
\hline Model Türü: & Model Türü: & Model Türü: & Model Türü: \\
\hline $\begin{array}{l}\text { Duyguların } \\
\text { yönetilmesine } \\
\text { ilişkin bir model }\end{array}$ & $\begin{array}{l}\text { Davranışların } \\
\text { yönetilmesine } \\
\text { ilişkin bir model }\end{array}$ & $\begin{array}{l}\text { Örgütsel ve bireysel } \\
\text { faktörlere ilişkin } \\
\text { bir model }\end{array}$ & $\begin{array}{l}\text { Karma } \\
\text { bir model }\end{array}$ \\
\hline Temel & \multirow{7}{*}{$\begin{array}{l}\text { Temel Boyutları: } \\
\text { Yüzeysel Davranış } \\
\text { Derinlemesine Davranış } \\
\text { Samimi Davranış }\end{array}$} & Temel Boyutlari: & Temel Boyutları \\
\hline Boyutları: & & \multirow{3}{*}{$\begin{array}{l}\text { Duyguların } \\
\text { gösterilişindeki } \\
\text { sıklık }\end{array}$} & Yüzeysel Davranış \\
\hline Yüzeysel & & & Derinlemesine \\
\hline Davranış & & & Davranış \\
\hline \multirow[t]{3}{*}{$\begin{array}{l}\text { Derinlemesine } \\
\text { Davranış }\end{array}$} & & $\begin{array}{l}\text { Belirlenen } \\
\text { duygusal davranış } \\
\text { kurallarına } \\
\text { verilen dikkat }\end{array}$ & \\
\hline & & $\begin{array}{l}\text { Yansıtılması } \\
\text { gereken duyguların } \\
\text { çeşitliliği }\end{array}$ & \\
\hline & & Duygusal çelişki & \\
\hline Genel Özelliği & Genel Özelliği & Genel Özelliği & Genel Özelliği \\
\hline $\begin{array}{l}\begin{array}{l}\text { Duygusal } \\
\text { emeğin }\end{array} \\
\text { kurumlara } \\
\text { olumlu, } \\
\text { çalışanlar } \\
\text { için ise } \\
\text { olumsuz } \\
\text { sonuçlar } \\
\text { doğurduğu } \\
\text { ifade } \\
\text { edilmektedir. }\end{array}$ & $\begin{array}{l}\text { Duygusal emek } \\
\text { duyguların } \\
\text { yönetimi olarak } \\
\text { değerlendirilmekte } \\
\text { ve sadece çalışanlar } \\
\text { üzerinde olumlu veya } \\
\text { olumsuz sonuçlara } \\
\text { (duygusal çelişki) } \\
\text { neden olabilir. }\end{array}$ & $\begin{array}{l}\text { Sergilenen her türlü } \\
\text { davranış için } \\
\text { belirli bir çaba dü- } \\
\text { zeyi olmalıdır. } \\
\text { Bireysel ve örgütsel } \\
\text { faktörler } \\
\text { duygusal emek için } \\
\text { önem } \\
\text { arz etmektedir. }\end{array}$ & $\begin{array}{l}\text { Diğer yaklaşımların } \\
\text { hepsini } \\
\text { bir araya getirmiştir } \\
\text { ve duygusal emeği } \\
\text { duygu düzenleme } \\
\text { süreci olarak } \\
\text { tanımlamıştır. }\end{array}$ \\
\hline
\end{tabular}

Yukarıda ki özet tabloda da yer aldığı gibi; duygusal emek kavramına ilişkin çalışmalar, odak noktası açısından faklı boyut ve modellere sahip olup, çalışma kapsamında duygusal emeğin yüzeysel davranış, derinlemesine davranış ve doğal (samimi) davranış olmak üzere üç boyutu esas alınmıştır. Yüzeysel davranış; çalışanın görevini icra ederken bireysel duygularının değişmemesine ve isteksiz olmasına rağmen olumlu ve güler yüzlü bir ifade takınması, gerçek hislerini saklaması, sahte duygular sergilemesidir (Mroz ve Kaleta, 2016, Grandey, 2000, Kim ve diğerleri, 
2017, s.3). Yüzeysel davranış; suçluluk duygusu, memnuniyetsizlik, daha az müşteri memnuniyeti, daha az hizmet kalitesi şeklinde sonuçlara neden olmaktadır (Groth ve diğerleri, 2009, Guillaume, 2015, s.14 ). Derin davranış; yüzeysel davranışa oranla iş görenin göstermesi gereken davranışların duygularını hissetmeye çalışarak sergilemesi, içsel duygu ile gösterilen duygunun tutarlı olması durumu olarak ifade edilmektedir (Wang ve diğerleri, 2016; Neels, 2012, s.15). Derin davranış sergileyen çalışanların iş tatmin seviyelerinde artışın gözlemlendiği, tutarlı davranmaya çalıştıkları için daha az duygusal tükenme yaşadıkları ve derin davranışın iş tatminini arttırdığı, bütünsel olarak sergilenen derin davranışın olumlu etkiler yarattı̆̆1 gözlemlenmektedir (Bennett, 2014, s.88; Fineman, 2008, s.30; Scott ve Barnes , 2011, s.118). Samimi davranış ise; bireylerin sergiledikleri davranışlarda her zaman sergilemek zorunda oldukları kurallara yönelik bir uyarlama yapmak zorunda olmaksızın, bu davranışları samimi bir şekilde içlerinden geldiği şekilde sergilemeleri durumudur. Samimi veya doğal davranış, doğal olarak gösterilen ve duyguyu değiştirmede ayrıca bir çaba sergilemeyi gerektirmeyen davranış şeklini ifade etmektedir (Woo, 2013, s.43).

Yapılan çalışmalarda; yüzeysel davranış ile tükenmişlik arasında güçlü bir ilişkinin mevcut olduğu (Brotheridge ve Grandey, 2002), evli iş görenlerin bekarlara oranla daha fazla başarı odaklı olmaları sebebiyle yüksek oranda duygusal emek davranışı sergiledikleri (Ŏ̆uz ve Özkul, 2016, s.146), yaşı görece daha büyük olanların genç çalışanlara göre daha fazla duygusal emek davranışı gösterdiği ve bu durumun görece genç olan çalışanların duygusal tükenme ve işten ayrılma niyetlerini arttırdığ (Lee, 2016, s.1341), hizmet sektöründe faaliyette bulunan çalışanların demografik bir takım (miliyet, etnik köken, inanç vb) unsurlara göre tutum ve duygularında değişikliklerin mevcut olduğu (Sohn vd., 2016, s.600) tespit edilmiştir.

\section{Kültürel Zekâ Kavramı}

Çok kültürlü çalışma ortamlarında, örgüt içerisinde çalışanların işlerini etkin bir şekilde yapabilmeleri ve iyi bir performans sergilemeleri önemli olup, özellikle bu konu da yapılan çalışmaların "kültürler arası uyum, iş performansı, uluslararası görev süresini tamamlama, örgütsel bağl1lık, 
kültürler arası yeterlilik ve kültürel zekâ" kavramlarına odaklandığı görülmektedir (Caligiuri, Tarique ve Jacobs, 2009, s.252). Bu çalışma alanlarından biri olan Kültürel zekâ kavramına ilişkin temeller, "Cultural Intelligence: Individual Interactions Across Cultures (Kültürel Zekâ: Kültürler arasında Bireysel Etkileşimler)" adlı çalışma ile başlamış, özellikle çok uluslu şirketlerin sayılarının ve yeni iş kollarında farklı yeteneklerin buluşmasına yönelik ihtiyacın artması ile çok kültürlü ortamlarda çalışanların yeteneklerini etkin bir şekilde sergileyebilmeleri adına üzerinde çalışılması gereken bir konu olarak belirmiştir. Earley ve Soon (2003, s.59) kültürel zekay1; " bireyin yeni kültürel bağlama uyum yeteneği" olarak, Brooks (2004) "insanlarm etkileşim içerisinde bulunduklar kültürün değerlerine ve tutumlarma uygun şekilde uyarlanmış beceri (örneğin, dil veya kişiler arası beceriler) ve nitelikleri (örneğin belirsizliğe karşı toleransı, esneklik) sergileme yeteneği" olarak tanımlamaktadır. Livermore (2010, s.4) ise kültürel zekayı "çeşitli etnik, ulusal, örgüt kültürel ortamlarında etkili olabilme yeteneği", Thomas ve Inkson (2008, s.23) " bir kültürün anlaşılması sürecinde esnek ve yetenek sahibi olma, artan bir ivme ile kümülatif bir şekilde buna ilişkin bilgi seviyesini arttırma, etkileşim sürecinde uygun davranış biçimleri geliştirmek suretiyle uyum sağlama ve düşünce yapısını yeniden yapılandırma süreci" olarak tanımlamaktadır. Bu kavramın özelliklerini ise şu şekilde özetleyebiliriz (Livermore (2010, s.19):

- Titiz akademik çalışmalara dayanan farklı örnekler, zaman dilimleri ve kültürlerde test edilmiş geniş bir çerçeveye sahiptir.

- Çoklu zeka çalışmalarına dayanmakta ve zekanın "motivasyon, biliş, üst biliş ve davranış" unsurları ile bağlantılıdır.

- Kültürel bir anlayişa ilişkin bilgi sunumundan öte; liderin kişisel ilgi alanlarını, stratejik düşünmesini, kültürler arası durumları da içermektedir.

- Kişisel özelliklerden ziyade; eğitim ve deneyimlerle öğrenilen yeteneklere vurgu yapmaktadır.

- Belli bir kültüre ait çeşitli özelliklere odaklanmak yerine; bütüncül bir anlayış yetenek ve davranış geliştirme sürecine odaklanmaktadır.

Uzun süreli ve çok sayıda kültürler arası ve zekâ çalışmaları neticesinde; kültürel zekâdan bütüncül bir şekilde faydalanabilmek ve incelemek adına dört temel boyut ve bunların alt bileşenleri aşağıda yer alan Şekil 3'de ifade edilmiştir: 


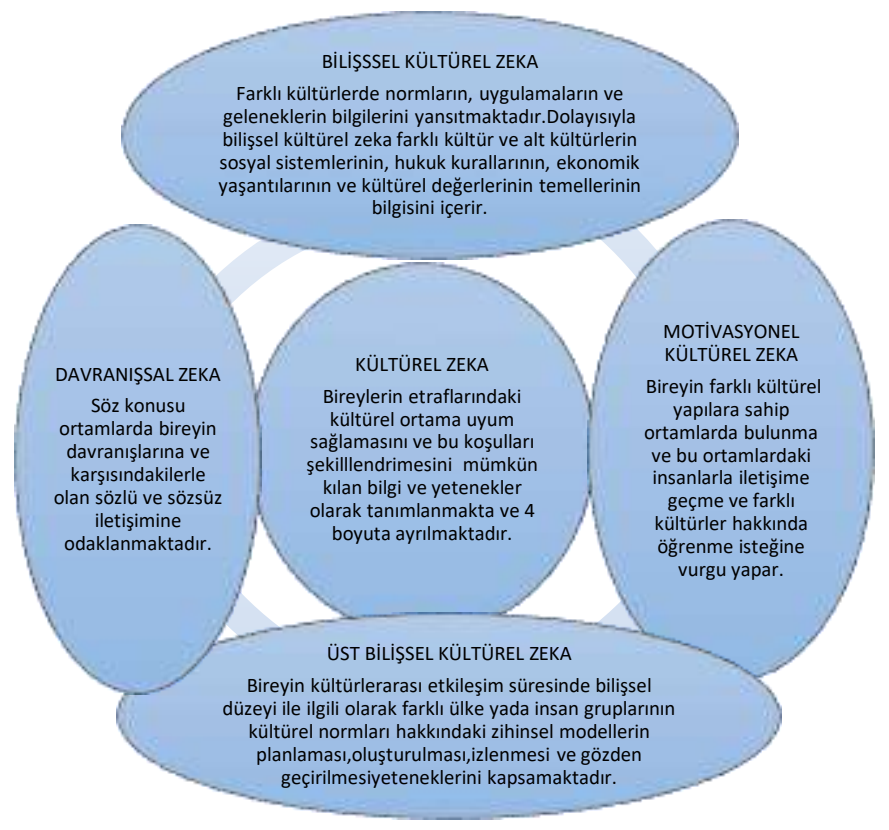

Şekil 1 : Kültürel Zekave Boyutları(Linn Van Dyne vd., 2010)

Kültürel zeka alanında farklı çalışmalar sürdürülmekte olup; iş seyahatlerinde bulunan çalışanlar üzerine yapılan bir çalışmada, tükenmişliği azalttı̆̆ (Tay vd, 2008, s.129), bireyin kültürler arası ortamlarda göstermiş olduğu performansında, örgüte karşı aidiyet hissi ve örgütsel vatandaşlık algısında artış sağladığı (Şahin vd.,2012), milliyet ve etnik köken açısından belirgin bir şekilde farklılaşan takımlarda, takım ve liderin performansına ilişkin bir çalışmada; yüksek kültürel zekaya sahip liderlerin kolektif takım amacı belirleme ve bu amaca uygun desteği elde etmede, diğer çalışan ve liderlerden daha başarılı oldukları (Groves ve Feyerherm, 2011, s.541542), kültürler arasında başarılı bir etkileşimin tesisinde kültürel zekanın gerekli olduğu (Triandis,2006, s.20) ve örgütte görev alan yabancı yöneticilerin sahip oldukları kültürel zekâsının, sergiledikleri liderlik performansının etkinliğini olumlu yönde etkilediği değerlendirilmektedir (Ersoy, 2014). 


\section{Duygusal Emek ve Kültürel Zeka Arasındaki İlişki}

Kültürel Zeka (CQ; "kültürel çeşitliliğin karakterize ettiği durumlarda kavrama, akıl yürütme ve etkin biçimde davranma yeteneklerine odaklanan özel bir zeka şekli" olarak tanımlanmakta ve üst bilişsel kültürel zeka, bilişsel kültürel zeka, motivasyonel kültürel zeka ve davranışsal kültürel zeka şeklinde dört boyutta incelenmektedir (Ang ve Linn, 2007, s.337). Sağlık sektöründe hasta ve yakınları ile ilk teması kuran ve ilgilenen çalışanlar üzerinde yapılan bir çalışmada; kültürel zeka, bir bireyin kültürel çeşitliliğe sahip ortamlarla ve durumlarla iç görü sahibi olma ve başa çıkma yeteneği olarak tanımlanmıştır (Bharwani ve Jauhari, 2013, s.831). Davranışın şekillenmesinde belirleyici bir etkiye sahip olan bireysel farklılıklar (kültürel zeka gibi); duygusal emeğin sergilenme sürecinde ki duygusal deneyimin öncülleri arasında yer alabilir (Bukcner, 2012). Duygusal anlayış ile duygu yönetimi arasında sebep sonuç ilişkisinin var olduğu, duygusal anlayışın, duygu yönetiminin öncülleri arasında yer aldığı ve bu ilişkinin, kültürler arası yeterlilik, kültürler arası uyum ve iş tatmini gibi olumlu çalışma sonuçlarına yol açtı̆̆ ifade edilmektedir (Reid, 2010). Sağlık sektöründe yürütülen bir çalışmada "kültürel yeterliliğin, duygusal emek aracılığıyla kültürler arası hizmet bağlamında duygusal tükenmeyi dolaylı olarak etkilemediği" ve kültürel yetkinliğin duygusal emeğin alt boyutlarından biri olan derinlemesine davranış ve performansla ilişkili olduğu, kültürel yetkinlik (kültürel zekanın yakın yapıları arasında yer alan) ile duygusal emek boyutlarından olan derinlemesine davranış arasındaki ilişkiye vurgu yaparak; yüksek kültürel yeterliliğe sahip olan bireylerin, daha yüksek seviyelerde derinlemesine davranış sergileme eğilimi içerisinde olacağını ifade etmiştir (McCance, 2010).

\section{Yöntem}

Araştırma, uluslararası bir örgüt bünyesinde görev yapan ve farklı kültürel ortamlardan gelen katılımcılar üzerinde gerçekleştirilmiştir. "Duygusal Emek" ile "Kültürel Zeka" değişkenleri arasındaki nedensel ilişkiyi test edilebilmek amacıyla araştırmaya katılmaya gönüllü olan ve İngilizce dil yeterliliği iyi olan kişilere her iki değişkene ilişkin ölçek ifadeleri sunulmuş ve katılımları sağlanmıştır. Araştırmada, 101 katılımcıdan elde 
edilen eksiksiz veri değerlendirmeye alınmıştır. Araştırmanın modeli aşağıdaki gibidir:

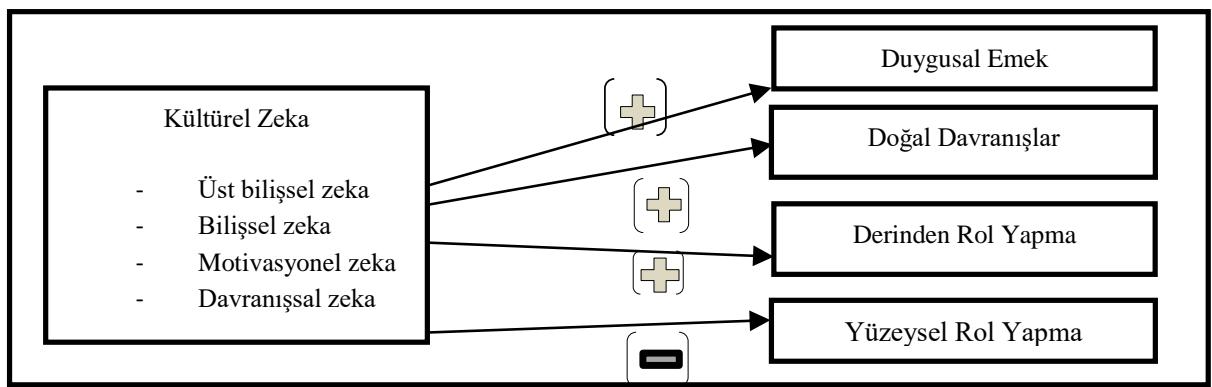

Şekil 2. Araştırma Modeli

Çalışmanın ana hedefi kültürlerarası ortamda çalışan personelin kültürel zekâ düzeyleri ile duygusal emek stratejileri arasındaki ilişkiyi ortaya koymaktır. Bu hedefe ulaşmak için literatür kısmında belirtilen değişkenler arasındaki ilişki göz önünde bulundurularak, aşağıdaki hipotezler kurulmuş ve toplanan veriler test edilmiştir.

- H1a:Çok Kültürlü Ortamlarda Çalışanların üst bilişsel kültürel zekâları, yüzeysel rol yapma davranışın etkilemektedir.

- H1b:Çok Kültürlü Ortamlarda Çalışanlarm bilişsel kültürel zekâları, yüzeysel rol yapma davranışını etkilemektedir.

- H1c:Çok Kültürlü Ortamlarda Çalışanlarm motivasyonel kültürel zekâları, yüzeysel rol yapma davranışın etkilemektedir.

- H1d:Çok Kültürlü Ortamlarda Çalışanların davranışsal kültürel zekâları, yüzeysel rol yapma davranışın etkilemektedir.

- H2a: Çok Kültürlü Ortamlarda Çalışanların üst bilişsel kültürel zekaları, derin davranışı etkilemektedir.

- H2b: Çok Kültürlü Ortamlarda Çalışanların bilişsel kültürel zekaları, derin davranışı etkilemektedir.

- H2c: Çok Kültürlü Ortamlarda Çalışanlarnn motivasyonel kültürel zekaları, derin davranışı etkilemektedir.

- H2d: Çok Kültürlü Ortamlarda Çalışanların davranışsal kültürel zekaları, derin davranışı etkilemektedir. 
- H3a:Çok Kültürlü Ortamlarda Çalışanların üst bilişsel kültürel zekaları, doğal(samimi) davranışı etkilemektedir.

- H3b: Çok Kültürlü Ortamlarda Çalşanlarm bilişsel kültürel zekaları, doğal(samimi) davranışı etkilemektedir.

- H3c:Çok Kültürlü Ortamlarda Çalışanlarm motivasyonel kültürel zekaları, doğal(samimi) davranışı etkilemektedir.

- H3d:Çok Kültürlü Ortamlarda Çalışanların davranışsal kültürel zekaları, doğal(samimi) davranışı etkilemektedir.

Hipotezlerin test edilebilmesi ve veri toplanması için iki farklı ölçek kullanılmıştır. Çalışmada, Ang ve arkadaşlarının (2007) geliştirmiş olduğu ve Türkçe uyarlamasını Şahin ve arkadaşlarının (2013) yaptığ1 20 maddelik ve 4 alt boyuta sahip Kültürel Zeka ölçeği kullanılmış, Duygusal emek ölçeği olarak ise; Diefendorff ve arkadaşları tarafından, Grandey, Kruml ve Geddes'ın duygusal emek ölçeklerinin bazı maddelerinin alınarak uyarlanması ve bazı maddelerin ise geliştirilmesi sonucu oluşturulan, yüzeysel rol yapma, derinden rol yapma ve doğal (samimi) duygular olmak üzere üç boyutlu ölçek kullanılmıştır.

\section{Bulgular}

Çalışmaya katılanların demografik özellikleri incelendiğinde; katılımcıların \%46'sı lise ve \%45'i üniversite mezunu, lisansüstü eğitim alanların oranı \%8,9 olduğu, yaş değişkeni incelendiğinde en fazla oranın \%37,6 ile 35-44 yaş grubunun teşkil ettiği, katılımcıların \%92'lik oranla erkek olduğu, katılımcıların \%81'nin evli olduğu ve özel şirketler aracılığıyla bölgede çalışanların oranın ise $\% 8^{\prime}$ olduğu tespit edilmiştir.

Ankette yer alan soruların beklendiği gibi ilgili boyutlara ayrıldığını doğrulamak için faktör analizi yapılmıştır. Faktör analizi sonuçlarına göre; kültürel zekâ ölçeği, 4 faktörle toplam varyansın \%64,61'ini açıklamaktadır (KMO değeri 0,92 ve Barlett testi sonucu $p<0,001$ düzeyindedir). Faktör güvenirliği Cronbach's Alpha değerleri ile test edilmiş, bunlar s1rasıyla $(0,81,0,83,0,75$ ve 0,88$)$ olup, ölçek ve faktörlerin güvenilir olduğu görülmüştür. Diefendorff ve arkadaşları tarafından, Grandey, Kruml ve Geddes'ın duygusal emek ölçeklerinin bazı maddeleri alınarak uyarlanan duygusal emek ölçeği; yüzeysel rol yapma 6, derinden rol yapma 4 ve doğal (samimi) duygular ise 3 madde ile ölçülmüştür. Ölçek orijinalinde 
olduğu gibi 3 boyutlu olarak tespit edilmiştir. Duygusal emek ölçeği, 3 faktörle toplam varyansın \%72,13 'ünü açılamaktadır (KMO değeri 0,81 ve Barlett testi sonucu $\mathrm{p}<0,001$ düzeyindedir). Faktör güvenirliği Cronbach's Alpha değerleri ile test edilmiş, bunlar sırasıyla $(0,85,0,89$ ve 0,75$)$ olup, ölçek ve faktörlerin güvenilir olduğu görülmüştür. Kolerasyon analizi sonuçları Tablo3'de yer almaktadır:

Tablo 2 :Korelasyon Sonuçlan

\begin{tabular}{|c|c|c|c|c|c|c|c|c|c|}
\hline & 1 & 2 & 3 & 4 & 5 & 6 & 7 & 8 & 9 \\
\hline Üstbilişsel & 1 & ,176 & , 241* & ,236* &, $545^{* *}$ & $318^{* *}$ &,- 151 & $270^{* *}$ &, $552^{* * *}$ \\
\hline Bilişsel & & 1 & $477^{*}$ &,- 116 &, $708^{* *}$ &,- 073 &,- 061 &,- 121 & ,073 \\
\hline Motivasyonel & & & 1 & ,019 & $769^{* *}$ & ,025 &,- 127 & ,045 & 153 \\
\hline Davranışsal & & & & 1 &, $403^{* *}$ & $608^{* *}$ &, $216^{*}$ &, $484^{* *}$ &, $454^{* *}$ \\
\hline Kültürel Zeka & & & & & 1 &, $295^{* *}$ &,- 043 & $221^{*}$ & $425^{* *}$ \\
\hline Duygusal Emek & & & & & & 1 &, $557^{* *}$ & $833^{* *}$ &, $441^{* *}$ \\
\hline Yüzeysel Davranış & & & & & & & 1 &, $213^{*}$ &, $300^{* *}$ \\
\hline Derinden Rol & & & & & & & & 1 & $282^{* * *}$ \\
\hline Doğal Davranış & & & & & & & & & 1 \\
\hline
\end{tabular}

Yapılan korelasyon analiz sonuçlarına göre; ana değişkenler olan Kültürel Zeka ve Duygusal Emek arasında hesaplanan Pearson Korelasyon katsayısı (r) 0,295 olarak tespit edilmiştir. Bu iki değişken arasında olumlu ve anlamlı orta seviyede bir ilişki olduğu tespit edilmiştir. Bu sonuçtan hareketle kişilerin kültürler arası ortamda duygusal emek gösterimlerinin, kültürel zeka düzeylerine göre farklılaştıkları görülmüştür.

\section{Tartışma}

Kültürel Zekâ boyutlarının, Duygusal Emek ve boyutları üzerindeki etkisini incelemek için regresyon analizleri yapılmıştır. Regresyon analizlerine ilişkin bulgular Tablo 3'de özetlenmektedir.

Kültürel zekanın alt boyutlarının duygusal emeğin alt boyutlarına olan etkisinin incelemek üzere yapılan regresyon analizleri incelendiğinde; 1 . Modelde; üst bilişsel zekanın yüzeysel rol yapma davranışını negatif yönde etkilediği $(\beta=,-198 ; p<0,05)$ görülmektedir. Benzer şekilde 1. modelde, davranışsal kültürel zekânın yüzeysel rol yapma davranışını pozi- 
tif yönde etkilediği $(\beta=, 271 ; p<0,01)$, ancak kültürel zekânın diğer boyutlarının yüzeysel rol yapma davranışı üzerindeki etkisine dair istatistiksel olarak anlamlı bir sonuca rastlanmadığı görülmektedir.

Tablo 3 : Regresyon Sonuçları

\begin{tabular}{lllllll}
\hline $\begin{array}{l}\text { Bağımsız } \\
\text { Değişkenler }\end{array}$ & \multicolumn{2}{c}{$\begin{array}{c}\text { Model } \\
\text { Yüzeysel } \\
\text { Rol Yapma }\end{array}$} & \multicolumn{2}{c}{$\begin{array}{c}\text { Model } \\
\text { Derin } \\
\text { Davranış }\end{array}$} & \multicolumn{2}{c}{$\begin{array}{c}\text { Model } \\
\text { Doğal } \\
\text { Davranış }\end{array}$} \\
\cline { 2 - 8 } & Beta & Sig. & Beta & Sig. & Beta & Sig. \\
\hline Üst bilişsel & $\mathbf{- 1 9 8}$ & $\underline{\mathbf{0 3}}$ & $\underline{\mathbf{1 7 9}}$ & $\underline{\mathbf{0 3}}$ & $\underline{\mathbf{4 6 0}}$ &, $\mathbf{0 0 0 ^ { * }}$ \\
\hline Bilişsel &, 058 &, 604 &,- 130 &, 201 &, 019 &, 830 \\
\hline Motivasyonel &,- 112 &, 322 &, 056 &, 579 &, 027 &, 767 \\
\hline Davranişsal & $\underline{\mathbf{2 7 1}}$ & $\underline{\mathbf{0 0 9}}$ & $\underline{\mathbf{4 2 6}}$ & $\underline{\mathbf{0 0 0}}$ & $\underline{\mathbf{3 4 7}}$ & $\underline{\mathbf{0 0 0}}$ \\
\hline R Square & & $\mathbf{0 , 0 9 9}$ & & $\mathbf{2 7 3}$ & &, $\mathbf{4 1 7}$ \\
\hline F Değeri & & $\mathbf{2 , 6 3 6}$ & & $\mathbf{9 , 0 0 9}$ & & $\mathbf{1 7 , 1 3 8}$ \\
\hline
\end{tabular}

2. Modelde, davranışsal kültürel zekânın $(\beta=, 426 ; p<0,01)$ ve üst bilişsel kültürel zekânın $(\beta=, 179 ; p<0,05)$ derin davranışı etkilediği, ancak diğer boyutların derin davranış üzerindeki etkiyi açıklar nitelikte bir sonuca rastlanmadığı, 3.modelde ise; üst bilişsel kültürel zekâ $(\beta=, 460 ; p<0,01)$ ve davranışsal zekânın doğal (samimi) davranışı pozitif yönde etkilediği $(\beta=, 347 ; p<0,01)$, ancak diğer boyutların doğal (samimi) davranış üzerindeki etkiyi açıklar nitelikte bir sonuca rastlanmadığ tespit edilmiştir. Kültürel Zekânın üst bilişsel ve davranışsal zeka boyutlarının doğal (samimi) davranışı \%42 oranında açıkladığı görülmüştür. Bu kapsamda H1a, H2a, $\mathrm{H} 3 \mathrm{a}, \mathrm{H} 1 \mathrm{~d}, \mathrm{H} 2 \mathrm{~d}, \mathrm{H} 3 \mathrm{~d}$ hipotezleri kabul edilmiştir.

\section{Sonuç}

Artan rekabet koşulları, maliyetleri düşürme ve kaliteli ürünler üretme, farklılık yaratma kaygısı ile hareket eden kar amacı güden ve gütmeyen örgütler, giderek küreselleşmekte, uluslararası bağlantılar kurmakta ve uluslararası iş birlikleri geliştirmektedir. Başarılı olmak, öğrenmek ve uluslararası bir projeyi gerçekleştirmek isteyen örgütlerin, bütün bunları başarabilmeleri için uluslararası ölçekte faaliyet gösterebilecek yetkinliklere ve hepsinden önemlisi farklı bir kültürel bağlamda ya da çok kültürlü bir ortamda çalışabilme yeteneğini ifade eden kültürel bir zekâya sahip olmaları gerekmektedir. Bu çalışmanın en önemli özelliği kültürel zekâ 
kavramını uluslararası alanda, çok kültürlü bir ortamda faaliyet gösteren üyeler üzerinde ele alması ve kültürel zekânın bireylerin duygusal emek gösterimleri veya davranışları üzerindeki etkisini ölçmesidir.

Araştırma sonuçları, bireyin kültürler arası etkileşim süresinde farklı ülke ya da insan gruplarının kültürel normları hakkındaki zihinsel modelleri planlanması, oluşturması, izlemesi ve gözden geçirmesi yeteneklerini kapsayan" üst bilişsel zekânın, bireylerin yüzeysel rol yapma davranışını negatif yönde etkilerken, derin davranış ve doğal (samimi) duygusal emek davranışını pozitif yönde etkilediğini göstermektedir. Bu sonuç bize, farklı kültürel değerlere ve tutumlara uygun şekilde uyarlanmış becerilere (örneğin, dil veya kişiler arası beceriler) ve niteliklere (örneğin belirsizliğe karşı toleransı, esneklik) sahip kültürel zekası yüksek bireylerin hissetmedikleri bir duyguyu gösteremediklerini, dolayısı ile yüzeysel duygusal emek davranışının düştügünü̈, aksine kültürel zekası, becerileri ve nitelikleri yüksek bireylerin içinde bulundukları ortamda yer alan birey ve yöneticilerine karşı empati geliştirebilme, sunmaları gereken duyguları aslında içselleştirme düzeylerinin (derin duygusal emek), göstermeleri gereken duyguları doğal olarak gösterme (doğal-samimi duygusal emek) davranışlarının arttığını göstermektedir. Bu sonuç McCance (2010)'inin çalışmasında ulaştığı; yüksek kültürel yeterliliğe sahip olan bireylerin, daha yüksek seviyelerde derinlemesine davranış sergileme eğilimi içerisinde olacağ

Araştırma sonuçları aynı zamanda, özellikle davranışsal kültürel zekânın yani, çok kültürlü ortamlarda çalışan diğer bireylere yönelik sözlü ve sözsüz iletişim kurma ve davranış sergileme becerisinin, bireylerin yüzeysel rol yapma, derin ve doğal duygusal emek davranışını arttırdığını göstermektedir. Bilişsel düzeyden davranışsal düzeye geçen kültürel zekanın, duygusal emeğin her boyutunu pozitif yönde etkilemesi, bu ortamlarda çalışan bireylerin her anlamda duygularını yönetebildiklerini ve giderek içinde bulundukları ortamı içselleştirerek, duygusal emek anlaminda derinlemesine ve doğal duygusal emek göstererek, ortama uyum sağladıklarını göstermektedir.

Duygusal emek kavramı, bir yandan çalışanların iş tatmini ve iş performansı seviyesini artırırken, tükenmişlik seviyesini azaltmakta, bireyin iş ortamını daha kaliteli hale getirerek, grup ve örgüt adına daha başarılı 
sonuçlar elde edilmesini sağlamaktadır. Bu anlamda duyguların yönetilmesi, empati kurulması, grup yada örgütte sergilenmesi gereken duyguların hissedilenlerle aynı olması yada doğal olarak kişinin duyguları ile benzeşmesi durumu oldukça önemli olup, iş yaşamına değer katan bir konudur. Diğer yandan kültürel zekâ kavramı henüz literatürde yeni bir kavram olup, konu ile ilgili araştırmalar henüz yeni yapılmakta ve konu gelişim göstermektedir. Bu anlamda kültürel zekâ ile duygusal emek kavramları arasında yol gösterici nitelikteki araştırma sayısı azdır. Bu araştırma bu anlamda her iki konu yazınına elde ettiği bulgular açısından katkı sunmakta ve kültürel zekânın duygusal emek davranışları açından oldukça önemli bir rol oynadığını göstermektedir. 


\title{
EXTENDED ABSTRACT
}

\section{The Effect of Cultural Intelligence Level on Emotional Labor in a Multicultural Environment}

\author{
Deniz Devrim Taşdemir - Hülya Gündüz Çekmecelioğlu -
}

İbrahim Y1kılmaz

Kocaeli Üniversity

The flow of capital, labor, services and ideas that are rapidly changing places and shapes with advanced technology and the opportunities offered by it in all areas of life; it leads to differentiation of the usual way of working and producing. This rapid change and creating cross-border business and creating value together creates a multicultural working environment that is increasing day by day. In this multicultural environment, the need to create sustainable competitive advantage from the differences in achieving the determined goals and objectives of organizations, has recently brought up issues such as uyum intercultural harmony, work performance, completion of international duty, organizational commitment, intercultural competence and cultural intelligence ve. studies have started to intensify in order to determine the steps to increase the efficiency and efficiency of human resources. Among the subjects of this study; The concept of intelligence, which is defined as uyum individual's adaptation to the new cultural context, the development of behavior appropriate to their values and attitudes, and the ability to be effective in multicultural environments, , is the current human resource and the new employees planned to join the organization, which has a critical role in achieving the goals and targets determined by the organizations, adapting to this environment and determining whether their cultural intelligence is appropriate for organizational culture is of great importance. In the relationship established by the individual with this multicultural environment; The concept of emotional labor, which is defined as lem regulating emotions, expressing the emotions that the organization deems necessary in interpersonal interaction, feeling as if they are part of the person and the environment they 
are interacting with and showing appropriate emotions also provides organizations with the best service, efficiency and efficiency needs. has become an important issue in terms of monitoring appropriate human resources strategies.

In this context; The concepts of cultural intelligence and emotional labor and the relationship between the variables were discussed in the literature. The results show that cultural intelligence levels of members in multicultural environments affect emotional labor behaviors. This result shows that cultural intelligence and emotional labor play an important role in reaching the goals and objectives of decision-makers in such environments and in making effective decisions and producing results. The results of the research show that cultural intelligence plays a distinctive role in the development of emotional labor behaviors that contribute positively to business life and directs the attention of managers to this concept.

One of these areas of study is the basis for the concept of cultural intelligencenstarted with especially with the increasing number of multinational companies and the need to meet different talents in different business lines It has emerged as an issue that needs to be worked on in order to effectively demonstrate the talents of employees working in multicultural environments. According to Earley and Soon (2003, s.59) cultural intelligence; "An individual's ability to adapt to the new cultural context,, Brooks (2004)" the ability to demonstrate skills (eg, language or interpersonal skills) and qualities (eg tolerance to uncertainty, flexibility) adapted to the values and attitudes of the culture with which people interact "It defines. Livermore (2010, s.4) states that cultural intelligence is yet the ability to be effective in various ethnic, national and organizational cultural environments "and according to Thomas and Inkson (2008, s.23)" have a flexible and talented understanding of a culture, and in a cumulative way the process of adapting and restructuring the thinking structure by developing appropriate behavioral patterns in the interaction process ".

Also in the context the concept of emotional labor is tried to be explained by different definitions and dimensions. According to James (1989), Ashforth and Humphrey (1993), "emotional labor; the main component is the regulation of emotions and in the process of coping with the emotions of others. According to Morris and Feldman (1996), individuals' efforts to 
express the necessary emotions during the interpersonal interaction, their plan and control ", for England and Farkas (1996) understanding others . Kruml and Geddes (2000) say, some efforts that employees have to feel in their integration processes, And to Eroğlu (2010), "employee effort to feel and convey the appropriate emotion in order to serve the stakeholders in the best way while applying the rules determined by the organization in which it works.

When regression analyzes conducted to examine the effect of sub-dimensions of cultural intelligence on sub-dimensions of emotional labor are examined; In model 1 ; It is seen that metacognitive intelligence negatively affects superficial role-playing behavior $(\beta=,-198 ; p<0.05)$. Similarly, in model 1, behavioral cultural intelligence positively influenced superficial role-playing behavior $(\beta=, 271 ; \mathrm{p}<0.01)$, but no statistically significant result was found regarding the effect of other dimensions of cultural intelligence on superficial role-playing behavior. In model 2 , behavioral cultural intelligence $(\beta=, 426 ; \mathrm{p}<0.01)$ and metacognitive cultural intelligence $(\beta=, 179 ; \mathrm{p}<0.05)$ affect deep behavior, but the other dimensions explain the effect on deep behavior. In the 3rd model; metacognitive cultural intelligence $(\beta=, 460 ; p<0.01)$ and behavioral intelligence positively affected natural (intimate) behavior $(\beta=, 347 ; \mathrm{p}<0.01)$, but other dimensions had no effect on natural (intimate) behavior. It was found that there is no conclusive result. It was seen that the metacognitive and behavioral intelligence dimensions of Cultural Intelligence explained natural (sincere) behavior by $42 \%$. In this context, the hypotheses H1a, H2a, H3a, H1d, H2d, H3d were accepted.

\section{Kaynakça / References}

Ang, S. ve Linn, V. D., (2008). conceptualization of cultural intelligence: definition, distinctiveness, and nomological network. In (S. Ang ve L. Van Dyne ed.) Handbook on Cultural Intelligence: Theory, Measurement and Applications, NY: M.E. Sharpe, Armonk.

Ashforth, B. ve Humphrey, R. (1993). Emotional labor in service roles: The influence of identity. Academy of Management, 18(1), 88-115.

Bennett, J. (2014). The impact of emotional labor and dissonance on job satisfaction upon criminal case manager. New Castle: Wilmington University. 
Bharwani, S. ve Jauhari, V. (2013). An exploratory study of competencies required to co-create memorable customer experiences in the hospitality industry. International Journal of Contemporary Hospitality Management, 25, 823-843

Buckner, J.E. (2012). Emotional labor and authentic leadership. (Yayınlanmamış Doktora Tezi), Louisiana TechUniversity.

Brooks, P. (2004) Cultural intelligence: A guide to working with people from other cultures, içinde (s.89), Maine:Intercultural Press.

Brotheridge, C., ve Grandey, A. (2002). Emotional labor and burnout: Comparing two perspectives of people work. Journal of Vocational Behavior, 60, 17-39.

Caligiuri,P.,Tarique,I. ve Jacobs,R. (2009). Selection for international assignments, Human Resource Management Review, 19, 252.

Earley, P. C. ve Ang, S. (2003). Cultural intelligence: Individual interactions across cultures. California:Stanford University Pres

England, P. ve Farkas, G. (1986). Households, employment, and gender: A social, economic, and demographic view. New York: Aldine.

Eroğlu, E. (2010). Örgütsel iletişimin işgörenlerin duygu gösterimlerinin yönetimine olan etkisi. Selçuk University Communication Faculty Academic Journal, 6 (3), 18-33.

Ersoy, A. (2014). Kültürel zekânın kültürlerarası liderlik etkinliği üzerindeki rolü: Konaklama işletmelerinde nitel bir araştırma. Journal of Yasar University, 9(35), 5999-6108.

Fineman, S.(2008). The emotional organization passion and power. Singapore: Blackwell Publishing Ltd.

Grandey, A. (2000). Emotional regulation in the workplace: A new way to conceptualize emotional labor. Journal of Occupational Health Psychology, 5(1), 95-110.

Groth, M., Hennig, T. T., ve Walsh, G. (2009). Customer reactions to emotional labor: The roles of employee acting strategies and customer detection accuracy. Academy of Management Journal, 52(5), 958-974.

Groves, K. S. ve Feyerherm, A. E. (2011). Leader cultural intelligence in context: testing the moderating effects of team cultural diversity on leader and team performance. Group \& Organization Management, 36(5), 535-566 
Guillaume, P. (2015). Permanent and seasonal employees: An investigation of differences in percieved organizational support: Job engagement and dedication to service quality. Iowa: St. Ambrose University.

Hochschild, A. R. (1983). The managed heart. California:University of California Press.

James, N. (1989). Emotional labour: Skill and work in the social regulation of feelings. Sociological Review, 37(1), 15-42.

Kim, H. J., Hur, W.-M., Moon, T.-W., ve Jun, J.-K. (2017). Is all support equal? The moderating effects of supervisor, coworker, and organizational support on the link between emotional labor and job performance. Business Research Quarterly, 20(2), 124-136

Kruml, S.M. ve Geddes, D. (2000). Exploring the dimensions of emotional labor: The heart of Hochschild's work. Management Communication Quarterly, 14, 8-49.

Lee, H. (2016). Effects of public service employee age and performance of emotional labor on job pride. Social Behavior and Personelity, 44(8), 1339-1348.

Livermore,D. (2010). Leading with cultural intelligence: The new secret to success içinde (s.19-20), NewYork:Amacoms.

McCance, A.S., (2010). Emotional labor in intercultural service encounters: An experience sampling study. (Yayınlanmış Doktora Tezi), University of Illinois at Urbana-Champaign.

Morris, J., ve Feldman, D. (1996). The dimensions, antecedents, and consequences of emotional labor. The Academy of Management Review, 21(4), 986-1010.

Mroz, J., ve Kaleta, K. (2016). Relationships between personality, emotional labor, work angagement and job satisfaction in service profession. International Journal of Occupational Medicine and Environmental Health, 29(5), 767-782.

Neels, V. (2012). The Effects of Age and Emotional Labor on Decision Making. Minneapolis: Walden University.

Oğuz, H., ve Özkul, M. (2016). Duygusal emek sürecine yön veren sosyolojik faktörler üzerine bir araştirma: Batı Akdeniz uygulaması. Süleyman Demirel Üniversitesi Vizyoner Dergisi, 7(16), 130-154. 
Reid, P. A., (2010). The role of emotional abilities in the development of crosscultural competence and their impact on cross-cultural adjustment and job satisfaction. (Yayınlanmış Doktora Tezi), Florida Institute of Technology-Melbourne

Savaş, A.H. (2012). İlköğretim okul müdürlerinin duygusal zekâ ve duygusal emek yeterliklerinin öğretmenlerin iş doyumuna etkisi: The effect of elementary school principals 'emotional intelligence and emotional labor competencies on teachers' job satisfaction. Doctoral Thesis Gaziantep University, Social Sciences Institute, Gaziantep.

Scott, B., ve Barnes, C. (2011). A multilevel field investigation of emotional labor, affect, work withdrawal, and gender. Academy of Management Journal, 54(1), 116-136.

Sohn, H.-K., Lee, T., ve Yoon, Y. (2016). Emotional labor and burnout: comparison between the countries of Japan and Korea. Journal of Travel and Tourism Marketing, 33(5), 597-612.

Şahin, F., Gürbüz, S., Ercan, Ü. ve Köksal, O. (2012). Kültürel zekâ, duygusal zekâ ve sosyal zekâdan farklı mıdır? 10. İşletmecilik Kongresi, Selçuk Üniversitesi, Konya, 356-365

Tay, C. M. ve Chia, A. (2008). Antecedents and consequences of cultural intelligence among short-term business travelers. In (S. Ang and L. Van Dyne Eds.), Handbook on Cultural Intelligence: Theory, Measurement and Alications (s.126-144). Armonk, NY: M.E.

Thomas,D.C. ve Inkson,K. (2008). Cultural intelligence: People skills for global business, içinde (s.23), California, Berrett-Koehler Publishers Inc.

Triandis, H.. (2006). Cultural Intelligence In Organizations. Group and Organization Management, 31, 20-26.

Wang, E., Berthon, P., Pitt, L., ve McCarthy, I. (2016). Service, emotional labor, and mindfulness. Business Horizons, 59(6), 655-661.

Woo, V. (2013). The perks and pitfalls of emotional labor: A conservation of resources approach. New York: Hofstra University. 


\section{Kaynakça Bilgisi / Citation Information}

Taşdemir, D. D., Çekmecelioğlu-Gündüz H. ve Yıkılmaz, İ. (2019). Çok kültürlü ortamda çalışanların kültürel zekâ düzeylerinin duygusal emek gösterimlerine etkisi. OPUS-Uluslararası Toplum Araştırmaları Dergisi, 12(18. UİK Özel Sayısı), 719-740. DOI: 10.26466-/opus.584460. 